\title{
Viral dominance of reassortants between canine influenza H3N2 and pandemic (2009) H1N1 viruses from a naturally co-infected dog
}

Woonsung $\mathrm{Na}^{1 \dagger}$, Kwang-Soo Lyoo ${ }^{2 \dagger}$, Eun-jung Song ${ }^{3}$, Minki Hong ${ }^{1}$, Minjoo Yeom³ ${ }^{3}$ Hyoungjoon Moon ${ }^{4}$, Bo-Kyu Kang ${ }^{4}$, Doo-Jin Kim ${ }^{1}$, Jeong-Ki Kim ${ }^{3^{*}}$ and Daesub Song ${ }^{3^{*}}$

\begin{abstract}
Background: Since avian-origin H3N2 canine influenza virus (CIV) was first identified in South Korea in 2008, the novel influenza virus has been reported in several countries in Asia. Reverse zoonotic transmission of pandemic H1N1 (2009) influenza virus (pH1N1) has been observed in a broad range of animal species. Viral dominance and characterization of the reassortants of both viruses was undertaken in the present study.

Findings: Here we describe the viral dominance of $23 \mathrm{CIV}$ reassortants between pH1N1 and canine H3N2 influenza viruses from a naturally co-infected dog. These results indicate that the $\mathrm{M}$ gene of pandemic H1N1 and the HA gene of canine H3N2 are predominant in the reassortants. Furthermore, unlike the original canine H3N2 virus, some reassortants showed high pathogenicity in mice.

Conclusions: This study suggests that continuous monitoring of influenza infection in companion animals may be necessary to investigate the potential of the emergence of novel influenza viruses.
\end{abstract}

Keywords: Influenza virus, Canine H3N2, Pandemic H1N1, Genetic dominance, Reassortment

\section{Findings}

Outbreaks of the infections caused by canine H3N2 (cH3N2) virus of avian origin, which causes severe respiratory symptoms in dog populations, have been continuously reported in South Korea, China, and Thailand since 2007, and inter-mammalian species transmission (dog to cat) has also been reported [1-4]. In August 2010, the World Health Organization announced that pandemic H1N1 (pH1N1) had moved into the post-pandemic period, although localized outbreaks of various magnitudes continue to occur. In particular, pH1N1 has been transmitted from humans to several animal species (termed "reverse zoonoses"), and many novel reassortant viruses have been generated [5-9]. Although most cases of reverse zoonoses have been reported in the pig population, the primary companion animals could be co-infected with $\mathrm{pH} 1 \mathrm{~N} 1$ and cH3N2 viruses due to their ecophysiological characteristics

\footnotetext{
*Correspondence: jkfrancis@korea.ac.kr; sds1@korea.ac.kr

${ }^{\dagger}$ Equal contributors

${ }^{3}$ Department of Pharmacy, College of Pharmacy, Korea University, Sejong,

Republic of Korea

Full list of author information is available at the end of the article
}

(synanthropicity). In this study, we isolated 23 distinct viral genotypes of influenza reassortants by using a nasal swab of a co-infected dog and characterized the genotypes of the reassortants.

From 2010 to 2012 in South Korea, we collected 213 nasal swabs from sick dogs showing clinical respiratory signs and tested the presence of canine influenza virus (CIV). Mixed infection with cH3N2 and pH1N1 influenza subtypes was confirmed in an individual dog (a swab specimen) using a commercial real-time reverse transcriptionpolymerase chain reaction (RT-PCR) kit (SensiFAST ${ }^{\mathrm{m} m}$; Bioline Inc.,Taunton, MA, USA). The real time RT-PCR targeted specific sequences of $\mathrm{HA}$ and NA genes for $\mathrm{pH} 1 \mathrm{~N} 1$ or cH3N2 influenza viruses. To determine the unidentified features, we performed single-plaque purification assays using the swab, and then the viruses were plaquepurified in MDCK cells.

Genotyping of plaque-purified viruses were performed as previously described by Hoffman et al. (2001) with slight modification [10]. Briefly, one-step RT-PCR (Qiagen) was conducted using universal primers, and each eight gene; 
polymerase basic 2 (PB2), polymerase basic 1 (PB1), polymerase acidic (PA), hemagglutinin (HA), nucleoprotein $(\mathrm{NP})$, neuraminidase (NA), matrix (M), and nonstructural (NS), were sequenced with the amplified and purified gene segments.

In total 97 different plaques were purified, and then genotypes of the viruses were established based on the eight gene segments (PB2, PB1, PA, HA, NP, NA, M, and NS) that originated from $\mathrm{pH} 1 \mathrm{~N} 1$ or $\mathrm{cH} 3 \mathrm{~N} 2$ virus. The plaques were classified into 23 different genotypic groups (Table 1). Of the 23 identified genotypic patterns, three genotypes, namely, VC7 ( 33\% of the clones contained the $\mathrm{M}$ gene from $\mathrm{pH} 1 \mathrm{N1}$; and the other genes were from $\mathrm{cH} 3 \mathrm{~N} 2), \mathrm{VC} 78(\sim 12.4 \%$ of the clones contained the $\mathrm{M}$ and NS genes from $\mathrm{pH} 1 \mathrm{~N} 1$; and the other genes were from $\mathrm{cH} 3 \mathrm{~N} 2$, and $\mathrm{VC} 1235678(\sim 12.4 \%$ of the clones contained the HA gene from $\mathrm{CH} 3 \mathrm{~N} 2$; and the other genes were from $\mathrm{pH} 1 \mathrm{~N} 1$ ) were found to be the

Table 1 Genetic dominance among the 23 genotypes that were reassorted with canine H3N2 and pandemic (2009) H1N1 influenza viruses

\begin{tabular}{|c|c|c|c|c|c|c|c|c|c|}
\hline \multirow[t]{2}{*}{ Genotype $^{a}$} & \multicolumn{8}{|c|}{ Influenza gene segments } & \multirow{2}{*}{$\begin{array}{l}\text { No. of } \\
\text { isolates } \\
\text { (\%) }\end{array}$} \\
\hline & $\overline{\mathrm{PB} 2}$ & PB1 & $\mathrm{PA}$ & $\mathrm{HA}$ & $\mathrm{NP}$ & $\mathrm{NA}$ & M & NS & \\
\hline 7 & $C$ & $C$ & $C$ & $C$ & $C$ & 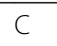 & $r$ & C & $2(32.9$ \\
\hline VC78 & C & C & $C$ & $C$ & C & $C$ & P & P & $12(12.37$ \\
\hline VC1235678 & $P$ & $P$ & $P$ & C & $P$ & $P$ & $P$ & $\mathrm{P}$ & $12(12.3$ \\
\hline VC235678 & $C$ & $P$ & P & C & $P$ & $P$ & $P$ & $P$ & $6(6.19)$ \\
\hline VC27 & C & $P$ & C & $C$ & C & C & $P$ & C & $5(5.15)$ \\
\hline VCnone & C & C & C & C & C & C & $C$ & C & $4(4.12)$ \\
\hline VC378 & $C$ & C & P & C & C & C & $P$ & $\mathrm{P}$ & $4(4.12)$ \\
\hline VC37 & C & C & $P$ & $C$ & C & $C$ & P & C & $3(3.09)$ \\
\hline VC123578 & P & $P$ & P & $C$ & $P$ & C & P & $\mathrm{P}$ & $3(3.09)$ \\
\hline VC23578 & C & $P$ & $P$ & $C$ & $P$ & $C$ & $P$ & $P$ & $2(2.06)$ \\
\hline VC678 & C & C & $C$ & $C$ & C & P & P & $\mathrm{P}$ & $2(2.06)$ \\
\hline VC12 & P & $\mathrm{P}$ & P & C & C & $P$ & $P$ & C & $10 \mathrm{C}$ \\
\hline VC123678 & $P$ & $P$ & $P$ & $C$ & $C$ & $\mathrm{P}$ & P & $P$ & $1(1.03)$ \\
\hline VC12378 & P & $P$ & $P$ & $C$ & C & $C$ & $P$ & P & $1(1.03)$ \\
\hline VC125678 & $\mathrm{P}$ & $P$ & C & C & $P$ & P & P & P & $1(1.03)$ \\
\hline VC13578 & $P$ & C & $P$ & $C$ & C & $C$ & $P$ & $P$ & $1(1.03)$ \\
\hline VC137 & P & $C$ & $P$ & $C$ & C & $C$ & P & C & $1(1.03)$ \\
\hline VC1378 & P & $C$ & P & $C$ & $C$ & $C$ & P & P & $1(1.03)$ \\
\hline$v(23)$ & C & $P$ & $P$ & C & C & C & P & C & $1(1.03)$ \\
\hline VC3578 & $C$ & C & $P$ & $C$ & $P$ & $C$ & P & $\mathrm{P}$ & $1(1.03)$ \\
\hline VC367 & C & $C$ & $P$ & $C$ & C & P & P & C & $1(1.03)$ \\
\hline VC578 & $C$ & C & $C$ & C & $P$ & C & P & $P$ & $1(1.03)$ \\
\hline VC67 & C & C & C & C & C & P & $P$ & C & $1(1.03)$ \\
\hline
\end{tabular}

anserted gene segments of pH1N1 were labeled as VC\#\#\# (e.g., VC37 refers to the $\mathrm{PA}(3)$ and $\mathrm{M}(7)$ genes from $\mathrm{pH} 1 \mathrm{~N} 1$; the other genes are from $\mathrm{cH} 3 \mathrm{~N} 2$ ) $C$ canine $\mathrm{H} 3 \mathrm{~N} 2$ influenza virus; $P$ pandemic $\mathrm{H} 1 \mathrm{~N} 1$ influenza virus most frequently observed among the 97 isolates based on the plaques. Only four clones $(\sim 4.1 \%)$ contained all eight gene segments of cH3N2 (VCnone), while no clone containing all gene segments from $\mathrm{pH} 1 \mathrm{~N} 1$ was detected. These results indicate that an ecologically significant yield (93/97; $95.9 \%$ ) of the clones could be produced by recombination between $\mathrm{cH} 3 \mathrm{~N} 2$ and $\mathrm{pH} 1 \mathrm{~N} 1$. Additionally, the $\mathrm{M}$ and $\mathrm{PA}$ genes of $\mathrm{pH} 1 \mathrm{N1}$ were dominant in the reassortants between the $\mathrm{pH} 1 \mathrm{~N} 1$ and $\mathrm{cH} 3 \mathrm{~N} 2$ viruses (22 and 15 genotypes, respectively). Furthermore, 14 genotypes included the NS gene of pH1N1; ten included the PB1; nine included the PB2; eight included the NP; and eight included the NA. However, we did not detect any genotype pattern that included the HA gene of pH1N1 (Table 1). Overall, these results indicate that the $\mathrm{M}$ gene of pH1N1 and the HA gene of cH3N2 show genetic dominance in the reassortants between the $\mathrm{pH} 1 \mathrm{~N} 1$ and $\mathrm{cH} 3 \mathrm{~N} 2$ viruses.

Table 2 Viral characteristics of the 23 genotypes in vivo and in vitro

\begin{tabular}{|c|c|c|c|c|c|}
\hline \multirow[t]{2}{*}{ Genotype } & \multirow[t]{2}{*}{ Subtype } & \multicolumn{4}{|c|}{ Replicability and pathogenicity } \\
\hline & & HA titer & $\mathrm{TCID}_{50} / \mathrm{mL}$ & $E I D_{50} / \mathrm{mL}$ & $\mathrm{MLD}_{50}$ \\
\hline$\overline{V C 7}$ & $\mathrm{H} 3 \mathrm{~N} 2$ & $2^{10}$ & $10^{6.6}$ & $10^{8.5}$ & n.d. \\
\hline VC1235678 & $\mathrm{H} 3 \mathrm{~N} 1$ & $2^{9}$ & $10^{5.9}$ & $10^{7.25}$ & $10^{7.25}$ \\
\hline VC235678 & $\mathrm{H} 3 \mathrm{~N} 1$ & $2^{10}$ & $10^{5.8}$ & $10^{6.5}$ & n.d. \\
\hline VC78 & $\mathrm{H} 3 \mathrm{~N} 2$ & $2^{11}$ & $10^{6.6}$ & $10^{7.5}$ & n.d. \\
\hline VC123578 & $\mathrm{H} 3 \mathrm{~N} 2$ & $2^{10}$ & $10^{6.8}$ & $10^{7.5}$ & $10^{4.2}$ \\
\hline VC678 & $\mathrm{H} 3 \mathrm{~N} 1$ & $2^{9}$ & $10^{6.6}$ & $10^{8}$ & n.d. \\
\hline VC123678 & $\mathrm{H} 3 \mathrm{~N} 1$ & $2^{10}$ & $10^{6.4}$ & $10^{7.5}$ & $10^{4.9}$ \\
\hline VC37 & $\mathrm{H} 3 \mathrm{~N} 2$ & $2^{11}$ & $10^{7.8}$ & $10^{8}$ & $10^{7}$ \\
\hline VCnone & $\mathrm{H} 3 \mathrm{~N} 2$ & $2^{10}$ & $10^{6.8}$ & $10^{6.5}$ & n.d. \\
\hline VC3578 & H3N2 & $2^{10}$ & $10^{6.8}$ & $10^{7.5}$ & n.d. \\
\hline VC12367 & $\mathrm{H} 3 \mathrm{~N} 1$ & $2^{10}$ & $10^{7}$ & $10^{7.75}$ & $10^{5.5}$ \\
\hline VC378 & $\mathrm{H} 3 \mathrm{~N} 2$ & $2^{9}$ & $10^{7.5}$ & $10^{8}$ & $10^{4.25}$ \\
\hline VC27 & H3N2 & $2^{10}$ & $10^{5.8}$ & $10^{8}$ & n.d. \\
\hline VC237 & $\mathrm{H} 3 \mathrm{~N} 2$ & $2^{10}$ & $10^{6.8}$ & $10^{7.5}$ & $10^{7.26}$ \\
\hline VC137 & $\mathrm{H} 3 \mathrm{~N} 2$ & $2^{9}$ & $10^{6.8}$ & $10^{8.5}$ & n.d. \\
\hline VC1378 & H3N2 & $2^{9}$ & $10^{7.2}$ & $10^{8.25}$ & $10^{7.75}$ \\
\hline VC12378 & H3N2 & $2^{10}$ & $10^{6.8}$ & $10^{7.5}$ & n.d. \\
\hline VC23578 & H3N2 & $2^{9}$ & $10^{6.4}$ & $10^{7.25}$ & n.d. \\
\hline VC125678 & $\mathrm{H} 3 \mathrm{~N} 1$ & $2^{8}$ & $10^{6.2}$ & $10^{6.5}$ & $10^{4}$ \\
\hline VC13578 & H3N2 & $2^{9}$ & $10^{6.9}$ & $10^{7.25}$ & $10^{6.85}$ \\
\hline VC367 & $\mathrm{H} 3 \mathrm{~N} 1$ & $2^{10}$ & $10^{6.6}$ & $10^{7.5}$ & n.d. \\
\hline VC578 & H3N2 & $2^{10}$ & $10^{6.6}$ & $10^{8.75}$ & n.d. \\
\hline VC67 & H3N1 & $2^{8}$ & $10^{6.9}$ & $10^{8.5}$ & n.d. \\
\hline
\end{tabular}

$E I D_{50} 50 \%$ egg infectious dose; $H A$ hemagglutinin; $M L D_{50} 50 \%$ mouse lethal dose; $n$.d. not determined; $T C I D_{50} 50 \%$ tissue culture infectious dose 
To examine the in vitro replicability and pathogenicity of a representative clone from each group, we determined HA titers and infectious and lethal doses. HA titers were measured using chicken red blood cells. The infective dose was measured using MDCK cells or embryonated chicken eggs and is presented as the $50 \%$ tissue culture infectious dose $\left(\mathrm{TCID}_{50}\right)$ or the $50 \%$ egg infectious dose $\left(\mathrm{EID}_{50}\right)$. The lethal dose was determined using mice and is presented as the $50 \%$ mouse lethal dose $\left(M L D_{50}\right)$. The infective and lethal doses were calculated using the ReedMuench method [11]. The clones examined replicated relatively well in mammalian cells and chicken embryos, as indicated by the HA titers, TCID 50 , and $\mathrm{EID}_{50}$, which were within the range of $2^{8}-2^{11}, 10^{5.8}-10^{7.8}$, and $10^{6.5}-10^{8.75}$, respectively (Table 2). However, these clones displayed a broad spectrum of changes in body weight and pathogenicity (asymptomatic to severe) in a mouse model (Fig. 1).

For viral pathogenicity in mice, 6-week-old C57BL/6 mice ( $n=6$ per group) were intranasally inoculated with $10^{6.5} \mathrm{EID}_{50}$ of virus. Mice were monitored daily for 14 days for changes in weight and mortality. The experiments conducted in animals were approved by an independent Animal Care and Use Committee and followed the guidelines of the Korea Research Institute of Bioscience and Biotechnology (Approval number 6015). In particular, mice infected with VC123578, VC378, or VC125678 showed severe clinical signs and experienced $100 \%$ mortality within 8 days post-inoculation (Fig. 2). The mortality of other genotypes, namely, VC1235678, VC367, VC12367, VC37, VC123678, and VC13578 ranged from 17 to $67 \%$, while no
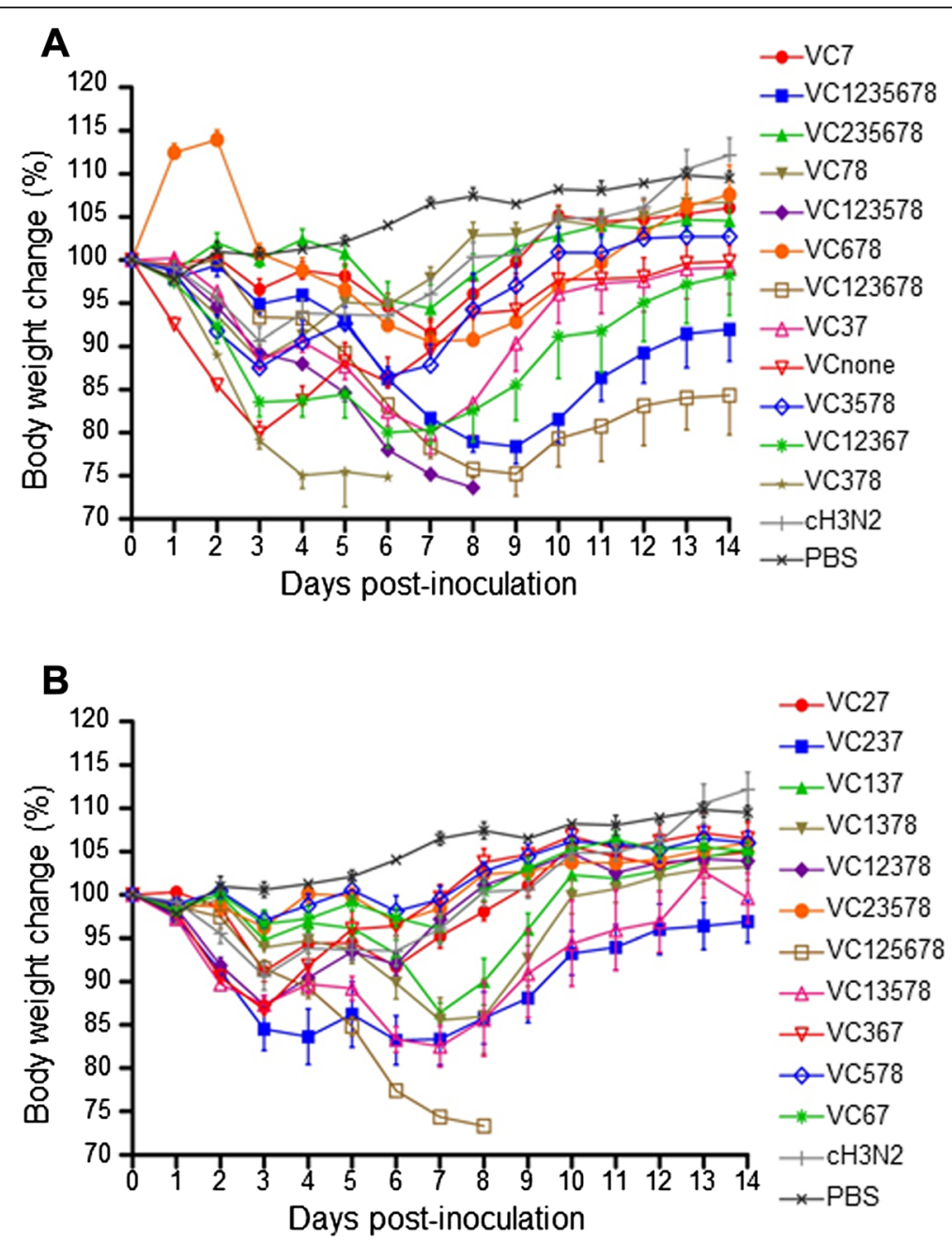

Fig. 1 Body weight changes in mice. Mice ( $n=6$ per group) were inoculated intranasally with $10^{6.5} \mathrm{EID}_{50}$ of each virus or PBS and monitored daily for 14 days for changes in body weight. Panel a shows body weight changes of groups of mice infected with VC7, VC1235678, VC235678, VC78, VC123578, VC678, VC123678, VC37, VCnone, VC3578, VC12367 or VC378. Panel b reveals those of groups of mice infected with VC27, VC237, VC137, VC1378, VC12378, VC23578, VC125678, VC13578, VC367, VC578 or VC67. The changes are represented as the percentage of weight on the day of inoculation (day zero), and the average of each group is shown 


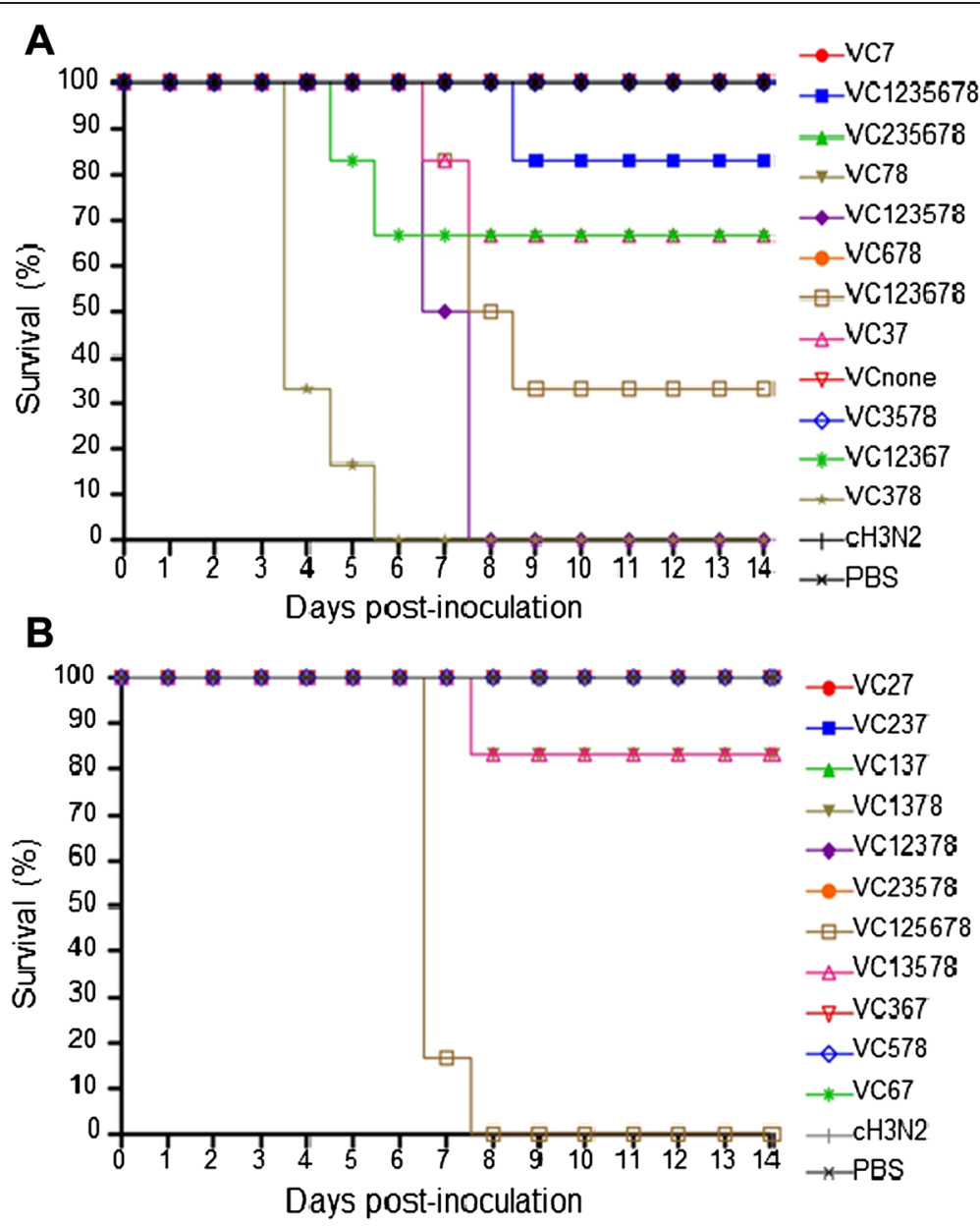

Fig. 2 Survival rates of mice. Mice ( $n=6$ per group) were inoculated intranasally with $10^{6.5}$ EID 50 of each virus or PBS and monitored daily for 14 days or until death. Panel a shows survival rates of groups of mice infected with VC7, VC1235678, VC235678, VC78, VC123578, VC678, VC123678, VC37, VCnone, VC3578, VC12367 or VC378. Panel b reveals those of groups of mice infected with VC27, VC237, VC137, VC1378, VC12378, VC23578, VC125678, VC13578, VC367, VC578 or VC67

morbidity or mortality was observed for the other genotypes including the original $\mathrm{cH} 3 \mathrm{~N} 2$ virus.

The routine surveillance for CIV by my colleagues has been conducted under the support of Ministry of Health and Welfare and Ministry of Science, ICT \& Future Planning, Republic of Korea. In the present study, we isolated CIV reassortants from a dog that the co-infection of $\mathrm{pH} 1 \mathrm{~N} 1$ and $\mathrm{cH} 3 \mathrm{~N} 2$ viruses was confirmed through the surveillance as well as genetic recombination and analyzed the patterns of genetic recombination between $\mathrm{cH} 3 \mathrm{~N} 2$ and $\mathrm{pH} 1 \mathrm{~N} 1$ viruses. Collectively, the $\mathrm{M}$ gene of $\mathrm{pH} 1 \mathrm{~N} 1$ and the HA gene of $\mathrm{cH} 3 \mathrm{~N} 2$ are responsible for viral dominance, and this tendency was very similar to that reported in previous studies. For example, Ducatez et al. [6] reported multiple reassortants between $\mathrm{pH} 1 \mathrm{~N} 1$ and swine endemic influenza viruses; in particular, of seven distinct viral genotypes, each included the $M$ gene from $\mathrm{pH} 1 \mathrm{~N} 1$ and $6,5,4,3,2$, and 1 genotypes included the PA, NS, NP, $\mathrm{PB} 1, \mathrm{~PB} 2$, and HA genes from $\mathrm{pH} 1 \mathrm{~N} 1$, respectively. The limited selection of the HA gene segment from pH1N1 was also consistent with that observed in previous studies involving the reassortants between $\mathrm{pH} 1 \mathrm{~N} 1$ and other influenza viruses $[6,12]$.

Genomic analysis of plaque-purified clones demonstrated 23 different genotypes of influenza viruses. All genotypes showed high infectivity by in vitro inoculation using MDCK cells or embryonated chicken eggs. However the genotypes displayed a broad spectrum of pathogenicity in vivo examination. Because multiple genetic exchanges had occurred in the clones, it is difficult to identify the reassortant of one or some gene segments that play a role in virulence in mice. Upon molecular analyses for the clones, pathogenicity-related point mutations (e.g., 591R or $591 \mathrm{~K}$ within the PB2 protein) were found in the gene segments from pH1N1 [13], although other known pathogenicity-related mutations (e.g., 158G, $627 \mathrm{~K}$, and $701 \mathrm{~N}$ within the PB2 protein; 66S within the PB1 protein; and 97I within the PA protein) 
were not observed in the clones [14-16]. However, the mutations did not contribute to the differences in the pathogenicity of the genotypes observed during in vivo and in vitro examinations.

In our previous study in 2011, it was reported that a novel H3N1 CIV reassorted with pH1N1 and cH3N2 [8]. The isolate can be categorized under the $\mathrm{VC} 1235678$ genotype. Dogs inoculated with H3N1 CIV did not show notable clinical symptoms, while nasal virus shedding and mild histopathological lesions were observed following the experimental inoculation in host animals. Therefore, it needs to investigate virologic and pathologic examinations for CIV reassortants of the present study using animal models in further study.

In most industrialized countries, companion animals are an integral part of family life, sharing our lifestyles, bedrooms, and beds [17]. We had previously shown the possibility of natural reassortment between pH1N1 and cH3N2 in a dog. Thus, these results probably imply that a primary companion animal, which lives in closer proximity to humans than do pigs, might act as a mixing vessel or serve as a source of novel influenza A virus in humans. Furthermore, our findings emphasize that intensive monitoring for influenza infection in companion animals is necessary to investigate the potential for the emergence of novel human influenza strains.

\section{Competing interests}

The authors declare that they have no competing of interests.

\section{Authors' contributions}

$\mathrm{WN}$ and $\mathrm{KL}$ analyzed the data and wrote the manuscript. In vivo and in vitro experiments were conducted by ES, MY, HM and $\mathrm{MH}$, and genetic analyses were performed by ES, BK, and DK. JK and DS designed and the experiments. All authors read and approved the final manuscript.

\section{Acknowledgments}

This work was supported by the Korea Healthcare Technology R\&D Project, Ministry of Health and Welfare, Republic of Korea (Grant No. A103001) and by 2013 KOREA-CHINA JOINT RESEARCH PROGRAM funded by the Ministry of Science, ICT \& Future Planning (2013K1A3A1A20046998).

\section{Author details}

${ }^{1}$ Korea Research Institute of Bioscience and Biotechnology, Daejeon, Republic of Korea. ${ }^{2}$ Korea Zoonosis Research Institute, Chonbuk National University, Iksan, Republic of Korea. ${ }^{3}$ Department of Pharmacy, College of Pharmacy, Korea University, Sejong, Republic of Korea. ${ }^{4}$ Green Cross Veterinary Products, Yong-In, Republic of Korea.

Received: 6 April 2015 Accepted: 15 July 2015

Published online: 04 September 2015

\section{References}

1. Bunpapong N, Nonthabenjawan N, Chaiwong S, Tangwangvivat R, Boonyapisitsopa S, Jairak W, et al. Genetic characterization of canine influenza A virus (H3N2) in Thailand. Virus Genes. 2014;48:56-63.

2. Li S, Shi Z, Jiao P, Zhang G, Zhong Z, Tian W, et al. Avian-origin H3N2 canine influenza A viruses in Southern China. Infect Genet Evol. 2010;10:1286-8.

3. Song D, Kang B, Lee C, Jung K, Ha G, Kang D, et al. Transmission of avian influenza virus (H3N2) to dogs. Emerg Infect Dis. 2008;14:741-6.
4. Song DS, An DJ, Moon HJ, Yeom MJ, Jeong HY, Jeong WS, et al. Interspecies transmission of the canine influenza H3N2 virus to domestic cats in South Korea, 2010. J Gen Virol. 2011;92:2350-5.

5. Berhane Y, Ojkic D, Neufeld J, Leith M, Hisanaga T, Kehler H, et al. Molecular characterization of pandemic $\mathrm{H} 1 \mathrm{~N} 1$ influenza viruses isolated from turkeys and pathogenicity of a human $\mathrm{pH} 1 \mathrm{~N} 1$ isolate in turkeys. Avian Dis. 2010;54:1275-85

6. Ducatez MF, Hause B, Stigger-Rosser E, Darnell D, Corzo C, Juleen K, et al. Multiple reassortment between pandemic (H1N1) 2009 and endemic influenza viruses in pigs, United States. Emerg Infect Dis. 2011;17:1624-9.

7. Howard WA, Essen SC, Strugnell BW, Russell C, Barass L, Reid SM, et al. Reassortant Pandemic (H1N1) 2009 virus in pigs, United Kingdom. Emerg Infect Dis. 2011;17:1049-52.

8. Song D, Moon HJ, An DJ, Jeoung HY, Kim H, Yeom MJ, et al. A novel reassortant canine $\mathrm{H} 3 \mathrm{~N} 1$ influenza virus between pandemic $\mathrm{H} 1 \mathrm{~N} 1$ and canine H3N2 influenza viruses in Korea. J Gen Virol. 2012;93:551-4.

9. Starick E, Lange E, Fereidouni S, Bunzenthal C, Hoveler R, Kuczka A, et al. Reassorted pandemic (H1N1) 2009 influenza A virus discovered from pigs in Germany. J Gen Virol. 2011;92:1184-8.

10. Hoffmann E, Stech J, Guan Y, Webster RG, Perez DR. Universal primer set for the full-length amplification of all influenza A viruses. Arch Virol. 2001;146:2275-89.

11. Thakur AK, Fezio WL. A computer program for estimating LD50 and its confidence limits using modified Behrens-Reed-Muench cumulant method. Drug Chem Toxicol. 1981;4:297-305

12. Ilyushina NA, Ducatez MF, Rehg JE, Marathe BM, Marjuki H, Bovin NV, et al. Does pandemic $\mathrm{A} / \mathrm{H} 1 \mathrm{~N} 1$ virus have the potential to become more pathogenic? MBio. 2010;1.

13. Song W, Wang P, Mok BW, Lau SY, Huang X, Wu WL, et al. The K526R substitution in viral protein PB2 enhances the effects of E627K on influenza virus replication. Nat Commun. 2014;5:5509.

14. Cheng K, Yu Z, Chai H, Sun W, Xin Y, Zhang Q, et al. PB2-E627K and PA-T971 substitutions enhance polymerase activity and confer a virulent phenotype to an H6N1 avian influenza virus in mice. Virology. 2014;468-470:207-13.

15. Bussey KA, Desmet EA, Mattiacio JL, Hamilton A, Bradel-Tretheway B, Bussey $\mathrm{HE}$, et al. PA residues in the $2009 \mathrm{H} 1 \mathrm{~N} 1$ pandemic influenza virus enhance avian influenza virus polymerase activity in mammalian cells. J Virol. 2011:85:7020-8.

16. Conenello GM, Zamarin D, Perrone LA, Tumpey T, Palese P. A single mutation in the PB1-F2 of H5N1 (HK/97) and 1918 influenza A viruses contributes to increased virulence. PLoS Pathog. 2007;3:1414-21.

17. Chomel BB, Sun B. Zoonoses in the bedroom. Emerg Infect Dis. 2011;17:167-72.

\section{Submit your next manuscript to BioMed Central and take full advantage of:}

- Convenient online submission

- Thorough peer review

- No space constraints or color figure charges

- Immediate publication on acceptance

- Inclusion in PubMed, CAS, Scopus and Google Scholar

- Research which is freely available for redistribution 